\title{
Patient Rights At The End Of Life: Provider Attitudes Toward End Of Life Decisions
}

Phil Rutsohn, Dr.Ph. (E-mail: prutsohn@marshall.edu), Marshall University Jean Yates, BSN, CNA, MS

\section{Introduction}

A

s a society we have recognize that an individual should have the right to provide informed consent regarding his or her care. This right extends to end of life decisions as long as they do not contradict current legal mandates (for example assisted suicide). Virtually all 50 states have passed legislation which allows patients to refuse life support and at the Federal level the Patient Self-Determination Act (1990) promotes this right at least within an Health Maintenance Organization environment. ${ }^{1}$

While both State and Federal legislation has been enacted to ensure that a patient's end of life wishes are adhered to, in practice they are often ignored. Provider attitudes and values, the desires of family members and basic indecision often conflict with the patient's wishes resulting in an extension of life contradictory to the desires of the patient. As a practical matter, legislation protecting patient end of life rights rarely provide sanctions for violating those rights. ${ }^{2}$ Although the Patient Self-Determination Act mandates that Medicare and Medicaid funds can be withheld if a provider fails to comply with a patient's wishes the sanction is never applied. ${ }^{3}$ Some states such as West Virginia have modified legislation to support the initiation of "wrongful living" suits by family members but to date these suits have not resulted in damage awards. ${ }^{4}$ In fact one could make a strong argument that a physician faces a far greater probability of being financially penalized for not extending a life than doing everything within his/her capability to extend that life!

Oregon legalized Physician Assisted Suicide in 1997 but physicians still report confusion concerning legal requirements, patient privacy and ability to secure lethal medications. ${ }^{5}$ In the Netherlands euthanasia is not legally permitted but appears to at least be informally condoned. Still, it represents a relatively small percentage of total deaths (2.5\% between 1990 and 1995). In fact, less than $.4 \%$ of deaths can be attributed to physician assisted suicide and $20 \%$ to withdrawing or withholding life support in the Netherlands. ${ }^{6}$

The controversy over patient end of life decisions may be one of individual orientation rather than professional membership. For example, in 1990 the Society of Critical Care Medicine (SCCM) affirmed the right of terminal and non-terminal patients to authorize or reject treatment. ${ }^{7}$ The American Dietetic Association issued a statement supporting a patient's right to refuse all medical treatment including artificial nutrition and hydration under certain circumstances in $1992 .^{8}$ Also in 1992 the American Nurses Association issued a position paper stating that nurses are not obligated to engage in extraordinary measures when artificial feeding is not necessary or is inappropriate. And, in 2000, the American College of Physicians and the American Society of Internal Medicine issued position papers recognizing a patient's right to voluntarily refuse food and fluids. ${ }^{9}$ The above citations are certainly not comprehensive but rather indicate that at the "professional" level there appears to be agreement.

Obviously, the disagreement between the patient's wishes and rights to control how he/she dies and others' abilities to delay death and prolong life is a function of the dynamics between individual providers, patients and significant others housed in a rather general legal environment. Frequently, physicians are unaware of a patient's desires and fail to communicate with the patient to ascertain their wishes. In 1984 Bedell found that while 89\% of terminal patients were competent to make end of life decisions at the time of admission, $76 \%$ were incompetent to

Readers with questions or comments are encouraged to contact the authors via email. 
make that decision at the time a Do Not Resuscitate (DNR) was needed! ${ }^{10}$ In a 1991 study Emanuel indicated that patients frequently cited the failure of a physician to ask about advanced directives to be the reason one was not completed. ${ }^{11}$

Both providers and significant others may be making decisions based on less than accurate information. For example, Meares discovered that primary caregivers often see feeding as a major focus of nurturing and therefore withholding intake is painful to them. ${ }^{12}$ And, although many providers and family members believe that dehydration is painful, studies have demonstrated that for terminally ill patients who gradually dehydrate with proportionate decreases in nutrients, electrolytes stay predominantly within normal ranges. ${ }^{1,14,15}$

When one combines the problem of ineffectiveness, the pressures placed on providers by significant others and the incorporation of the provider's individual constructs of truth, beneficence, justice and autonomy it's a wonder that a patient's wishes are ever manifested. The religious beliefs and cultural orientation of the responsible provider most certainly will have an effect on end of life decision-making. For example, the Chinese and some Middle Eastern cultures believe that it's incorrect to inform a patient of his/her impending death. ${ }^{16}$ Obviously this greatly inhibits the completion of advanced directives. In Europe, Roman Catholic physicians are likely to provide total treatment even if it is against the patient's wishes. ${ }^{17}$ In the United States Jewish physicians are more likely to withhold or withdraw life support than are Roman Catholic Physicians. ${ }^{18}$ Fukara found that although DNR orders are written for $72 \%$ of the patients who die in a Japanese hospital only $5 \%$ of these patients are involved in making the decision. ${ }^{19}$ In Hong Kong, it's considered rude and dangerous to tell someone they're dying. ${ }^{20}$ The examples are as varied as they are numerous but they all demonstrate that end of life decision making involves inputs beyond the patient that are influenced by value judgments often times beyond objective criteria.

One would assume that the determination of medical futility would contribute to reducing variability in the decision making process. Younger describes physiological futility as resulting when an intervention would not achieve the desired somatic goal and qualitative futility when a treatment may achieve an outcome but the outcome is not worth achieving. ${ }^{21}$ While these definitions may be readily accepted one can easily see that they provide wide latitude for the decision-maker. Determining whether there is a low likelihood that an intervention will result in a desired outcome and therefore is futile is by definition probalistic hence incorporates value judgments. Presently there is no clear case law regarding futility that may be used as guidelines. ${ }^{22}$

To a degree the availability of resources may play a role in decisions based on futility. Approximately $10 \%$ to $12 \%$ of all health care expenditures and $27 \%$ of Medicare expenditures are consumed by end-of-life care. ${ }^{23}$ As the 73 million baby boomers born between 1946 and 1964 reach retirement age and beyond, resource availability may become a dominant decision-making factor.

\section{Study Design}

The focus of this study emphasized a comparison of the socio-demographic characteristics of health providers and educational experiences with their perceptions concerning the absolute right of patients to make end-oflife decisions. Although the physician is the prime decision-maker in health care the investigators expanded their sample population to include other providers. As the "team" decision-making process becomes more pronounced in health care the perceptions of non-physicians should grow in importance.

The sample population for the study consisted of 138 health providers at a large federal health care facility. The sample included physicians, nurses, social workers, dietitians, pharmacists, members of ethics committees and hospital administrators. Respondents were contacted either personally or through in-house mail and requested to complete a 21 item questionnaire. Eight questions requested socio-demographic information and 13 questions focused on perceptions regarding end of life care. Socio-demographic questions were designed to elicit fixed answers while perception questions were presented in a five alternative Likert-type scale ranging from "strongly agree" to "strongly disagree". Chronbach's alpha coefficient of .65 suggests satisfactory reliability of the questionnaire.

\section{Socio-Demographic Characteristics Of The Sample Population}


As indicated above the sample population consisted of 138 health care providers. Fifty-five percent of the respondents were females and $45 \%$ males. The age distribution represented a reasonable bell shaped curve with $2 \%$ under 25 years of age and 3.5\% over 65. The majority (54.3\%) fell within the age range of 31 to 49 years old. Religious preference was heavily weighted toward a protestant orientation $(64.5 \%)$ with light representation among Jewish health care providers $(.8 \%)$. The researchers speculated that region of the country strongly influenced this characteristic.

The education level of the sample population was higher than one would expect for the population in general. Thirty-three percent of the respondents graduated from medical school with an additional $5 \%$ graduating from either schools of osteopathic medicine or allopathic medicine. Respondents with graduate degrees (other than physicians) represented $16 \%$ of the sample population with an additional $25 \%$ possessing a four-year college degree. In total, $79 \%$ of the respondents possessed at least a four-year college degree. Given the nature of the study and the environment within which the survey was conducted one would expect a high level of education among the sample population.

The majority of the respondents were trained/educated in the United States $(87.5 \%)$ with only $12.5 \%$ receiving either all or part of their training/education outside of the United States. Physicians (39\%) and registered nurses $(34 \%)$ were the dominant occupations among the sample population. Less than $6 \%$ of the respondents had been employed in health care for less than one year while over 33\% had more than 20 years of work experience.

\section{Perceptions Concerning End Of Life Care}

Overwhelmingly (96\%) the respondents believed that a patient has the absolute right to determine the care he/she receives at the end of life. Interestingly however, a large percentage were neutral (17\%) when asked if this right should be limited if resources were scarce. The remaining $83 \%$ were split over the issue with $40 \%$ supporting the patient's absolute right and $43 \%$ not supporting the patient's absolute right. At least for this group, the patient's absolute decision making rights may be tempered by the availability of resources. The group strongly supported the notion that a patient's wishes as outlined in their advance directive should always be followed (92\%) but were not as positive about this issue if the patient becomes incompetent and the surrogate decision-maker does not agree with the advanced directive (79\% would honor the patient's wishes). The drop from $92 \%$ to $79 \%$ may be indicative of the problem currently faced in health care when there is such a conflict. Variability among the respondents concerning discontinuance of life-sustaining measures increased when an advanced directive was absent and shifted substantially when faced with alternative actions. Although 92\% would follow the patient's wishes as outlined in an advanced directive only $71 \%$ would withhold mechanical ventilation without an advanced directive. If discontinuance of treatment involved withholding antibiotics or other medication in cases of futility the percent "agreeing" fell further (55\%) and the percent "disagreeing" increased from 15\% for withholding mechanical ventilation to 33\% for withholding medications. As indicated in the discussion above the withholding of nutrition at end of life may contradict the nurturing orientation of caregivers as well as family members. Only $39 \%$ of the respondents agreed with withholding food and IV fluids when further treatment would be futile and $49 \%$ disagreed with this intervention.

It appears that while the majority of providers would agree with adhering to a patient's wishes at end of life their support dwindles with variability. If the caregiver disagrees with the advanced directive fewer providers support the patient's decisions and as the behavior becomes more "personal" (withholding mechanical ventilation versus withholding food) providers become less willing to withhold treatment. Its interesting to note that we are more willing to starve a patient of oxygen (mechanical ventilation) then we are to starve them of food.

When asked if a physician should be the one to make the decision to discontinue life-sustaining measures when further treatment is futile, the group was fairly evenly distributed in their responses. Approximately $38 \%$ felt that he/she should make the decision and $41 \%$ felt that he/she should not make the decision. Interestingly, 29\% of the respondents believed that it was unacceptable for the physician to assist the patient to die a comfortable dignified death but a vast majority (92\%) felt that it was acceptable for the physician to provide palliative care to the patient 
even when it would accelerate death. Apparently the sample population viewed providing pain relief even when it accelerated death as being "different" from assisting a patient to die comfortably. This may be the result of an interpretation of the term "assisting" or it may be another example of the "personal" aspect of the decision making process that was demonstrated through the questions dealing withholding life sustaining interventions.

Physician assisted suicide, at least by the majority of the respondents $(63 \%)$, is not an acceptable end of life strategy. However almost $17 \%$ were neutral about this issue with $20 \%$ supporting the strategy. It would be interesting to compare the responses of health care providers and the general population concerning this issue. For a review of individual responses to each question the reader is referred to exhibit \#1.

\section{EXHIBIT 1}

\section{Provider Perceptions Concerning End Of Life Decisions}

1. A patient has the absolute right to determine the care he/she receives at the end of life:

\begin{tabular}{|l|c|c|}
\hline & Frequency & Percent \\
\hline Strongly Agree & 105 & $76.1 \%$ \\
\hline Agree & 27 & $19.6 \%$ \\
\hline Neutral & 1 & $.7 \%$ \\
\hline Disagree & 4 & $2.9 \%$ \\
\hline Strongly Disagree & 1 & $.7 \%$ \\
\hline Total & 138 & $100.0 \%$ \\
\hline
\end{tabular}

2. Access to beneficial health care services for the terminally ill should be limited when there are inadequate resources to meet all of the health care needs of society:

\begin{tabular}{|l|c|c|}
\hline & Frequency & Percent \\
\hline Strongly Agree & 5 & $3.6 \%$ \\
\hline Agree & 29 & $21.0 \%$ \\
\hline Neutral & 25 & $18.1 \%$ \\
\hline Disagree & 47 & $24.1 \%$ \\
\hline Strongly Disagree & 32 & $23.2 \%$ \\
\hline Total & 138 & $100.0 \%$ \\
\hline
\end{tabular}

3. A patient's absolute right to dictate or demand a specific treatment should be limited when there are inadequate resources to meet all of the health care needs of society:

\begin{tabular}{|l|c|c|}
\hline & Frequency & Percent \\
\hline Strongly Agree & 10 & $3.2 \%$ \\
\hline Agree & 50 & $36.2 \%$ \\
\hline Neutral & 23 & $16.7 \%$ \\
\hline Disagree & 36 & $26.1 \%$ \\
\hline Strongly Disagree & 19 & $13.8 \%$ \\
\hline Total & 138 & $100.0 \%$ \\
\hline
\end{tabular}

4. The patient's wishes as outlined in an advance directive should always be followed: 


\begin{tabular}{|l|c|c|}
\hline & Frequency & Percent \\
\hline Strongly Agree & 83 & $60.1 \%$ \\
\hline Agree & 43 & $31.2 \%$ \\
\hline Neutral & 7 & $5.1 \%$ \\
\hline Disagree & 4 & $2.9 \%$ \\
\hline Strongly Disagree & 1 & $.7 \%$ \\
\hline Total & 138 & $100.0 \%$ \\
\hline
\end{tabular}

5. Once the patient is incompetent to make decisions, the decisions of the surrogate decision maker should be honored even if they are not in agreement with the patient's advance directive:

\begin{tabular}{|l|c|c|}
\hline & Frequency & Percent \\
\hline Strongly Agree & 6 & $4.3 \%$ \\
\hline Agree & 18 & $13.0 \%$ \\
\hline Neutral & 5 & $3.6 \%$ \\
\hline Disagree & 69 & $50.0 \%$ \\
\hline Strongly Disagree & 40 & $29.0 \%$ \\
\hline Total & 138 & $100.0 \%$ \\
\hline
\end{tabular}

6. When all further treatment is futile, the physician should make the decision to discontinue life-sustaining measures:

\begin{tabular}{|l|c|c|}
\hline & Frequency & Percent \\
\hline Strongly Agree & 21 & $15.2 \%$ \\
\hline Agree & 45 & $32.6 \%$ \\
\hline Neutral & 15 & $10.9 \%$ \\
\hline Disagree & 42 & $30.4 \%$ \\
\hline Strongly Disagree & 15 & $10.9 \%$ \\
\hline Total & 138 & $100.0 \%$ \\
\hline
\end{tabular}

7. In the absence of an advance directive, withdrawing or withholding mechanical ventilation from a patient is acceptable if to continue further treatment would be futile:

\begin{tabular}{|l|c|c|}
\hline & Frequency & Percent \\
\hline Strongly Agree & 34 & $24.6 \%$ \\
\hline Agree & 64 & $46.4 \%$ \\
\hline Neutral & 19 & $13.8 \%$ \\
\hline Disagree & 16 & $11.6 \%$ \\
\hline Strongly Disagree & 5 & $3.6 \%$ \\
\hline Total & 138 & $100.0 \%$ \\
\hline
\end{tabular}

8. In the absence of an advance directive, withholding antibiotics or other medications is acceptable if to continue further treatment would be futile:

\begin{tabular}{|l|c|c|}
\hline & Frequency & Percent \\
\hline Strongly Agree & 36 & $18.8 \%$ \\
\hline Agree & 50 & $36.2 \%$ \\
\hline Neutral & 116 & $11.6 \%$ \\
\hline Disagree & 35 & $25.4 \%$ \\
\hline Strongly Disagree & 11 & $8.0 \%$ \\
\hline Total & 138 & $100.0 \%$ \\
\hline
\end{tabular}

9. In the absence of an advance directive, withholding food and IV fluids is acceptable if to continue further treat- 
ment would be futile:

\begin{tabular}{|l|c|c|}
\hline & Frequency & Percent \\
\hline Strongly Agree & 16 & $11.6 \%$ \\
\hline Agree & 38 & $27.5 \%$ \\
\hline Neutral & 16 & $11.6 \%$ \\
\hline Disagree & 50 & $36.2 \%$ \\
\hline Strongly Disagree & 18 & $13.0 \%$ \\
\hline Total & 138 & $100.0 \%$ \\
\hline
\end{tabular}

10. When all further treatment is futile, it is acceptable for the physician to assist the patient to die a comfortable, dignified death:

\begin{tabular}{|l|c|c|}
\hline & Frequency & Percent \\
\hline Strongly Agree & 48 & $34.8 \%$ \\
\hline Agree & 35 & $25.4 \%$ \\
\hline Neutral & 14 & $10.1 \%$ \\
\hline Disagree & 22 & $15.9 \%$ \\
\hline Strongly Disagree & 18 & $13.0 \%$ \\
\hline No Answer & 1 & $.7 \%$ \\
\hline Total & 138 & $99.3 \%$ \\
\hline
\end{tabular}

11. When all further treatment is futile, it is acceptable for the physician to provide palliative care (pain relief) to the patient even if the end result is an accelerated death:

\begin{tabular}{|l|c|c|}
\hline & Frequency & Percent \\
\hline Strongly Agree & 84 & $60.9 \%$ \\
\hline Agree & 44 & $31.9 \%$ \\
\hline Neutral & 7 & $5.1 \%$ \\
\hline Disagree & 1 & $.7 \%$ \\
\hline Strongly Disagree & 2 & $1.4 \%$ \\
\hline Total & 138 & $100.0 \%$ \\
\hline
\end{tabular}

12. Health care decisions at the end of life should be based on the ability of the patient, family, or a third party to pay for the services:

\begin{tabular}{|l|c|c|}
\hline & Frequency & Percent \\
\hline Strongly Agree & 2 & $1.4 \%$ \\
\hline Agree & 5 & $3.6 \%$ \\
\hline Neutral & 13 & $9.4 \%$ \\
\hline Disagree & 35 & $25.4 \%$ \\
\hline Strongly Disagree & 83 & $60.1 \%$ \\
\hline Total & 138 & $100.0 \%$ \\
\hline
\end{tabular}

13. When all further treatment is futile, it is acceptable for the physician to assist the patient in finding a means to end their life:

\begin{tabular}{|l|c|c|}
\hline & Frequency & Percent \\
\hline Strongly Agree & 12 & $8.7 \%$ \\
\hline Agree & 16 & $11.6 \%$ \\
\hline Neutral & 23 & $30.7 \%$ \\
\hline Disagree & 42 & $30.4 \%$ \\
\hline Strongly Disagree & 45 & $100.0 \%$ \\
\hline Total & 138 & $10 \%$ \\
\hline
\end{tabular}

Summary And Conclusions 
Given the limited sample population the outcomes of this study cannot be generalized to the overall population of health care providers but the data collected and analyzed does provide interesting information for further study. Health care providers respect the wishes of terminal patients but are less inclined to support those wishes when family or significant others are not in agreement. While self-determination and death with dignity seem to be principles widely supported the level of support at least for the sample group diminishes as the method of intervention becomes more "personal".

Further study with greater cultural and educational diversity would be beneficial. The authors would suggest cross-sectional studies incorporating a multiple of geographic regions emphasizing religious, cultural and occupational diversity.

\section{References}

1. Lens, V. \& Pollack, D. (2000). "Advance directives: Legal remedies and psychosocial interventions." Death Studies (July/August), Vol. 24 (5), pp. 377-379.

2. Lens, V. \& Pollack, D. (2000). "Advance directives: Legal remedies and psychosocial interventions." Death Studies (July/August), Vol. 24 (5), pp. 377-379.

3. Furrow, B., Greaney, T., Johnson, S., Jost, T., \& Schwartz, R. (1995). Health law. St. Paul, MN: West Publishing Company.

4. Lens, V. \& Pollack, D. (2000). "Advance directives: Legal remedies and psychosocial interventions." Death Studies (July/August), Vol 24 (5), pp. 377-379.

5. Ganzina, L., Nason, H., Schmidt, T., Kraemer, D., Delorit, M., Lee, M. (2000) "Physicians' experiences with the Oregon Death with Dignity Act." New England Journal of Medicine, Vol. 342, pp .557-563.

6. Curtis, J. \& Rubenfeld, G. (2001). Managing Death in the Intensive Care Unit: The Transition from Cure to Comfort. New York: Oxford University Press.

7. Quill, T \& Byock, I (2000). "Responding to intractable terminal suffering: the role of terminal sedation and voluntary refusal of food and fluids." Annals of Internal Medicine, Vol 132(5), pp.408-414.

8. American Dietetic Association (1992). "Issues in feeding the terminally ill adult." Journal of the American Dietetic Association, Vol 92(8), pp.996-1004.

9. Quill, T \& Byock, I (2000). "Responding to intractable terminal suffering: the role of terminal sedation and voluntary refusal of food and fluids." Annals of Internal Medicine, Vol 132(5), pp.408-414.

10. Bedell, S., \& Delbanco, T. (1984). "Choices about cardiopulmonary resuscitation in the hospital: When do physicians talk with patients?” New England Journal of Medicine. pp.1089-1093.

11. Emanuel, L., Barry, M., Stoeckle, J. Ettleson, L., \& Emanuel, E. (1991). "Advance directives for medical care: A case for greater use." New Journal of Medicine, 324(13), pp. 889-895.

12. Meares, C. (1997). "Primary caregiver perceptions of intake cessation in patients who are terminally ill." Oncology Nursing Forum, Vol 24(10), pp.1751-1757.

13. Smith, S. \& Andrews, M. (2000). "Artificial nutrition and hydration at the end of life." MedSurg Nursing (October), Vol 9(5), pp.233-245

14. Smith, S. (1995). "Patient-induced dehydration; Can it ever be therapeutic?" Oncology Nursing Forum, Vol 22(10), pp. 1487-1491

15. Smith, S. (1997). "Controversies in hydrating the terminally ill patient." Journal of Intravenous Nursing, Vol 20 (4), pp. 193-200.

16. Curtis, J. \& Rubenfeld, G. (2001). Managing Death in the Intensive Care Unit: The Transition from Cure to Comfort. New York: Oxford University Press.

17. Vincent, J. (1999). "Foregoing life support in Western European intensive care units: The results of an ethical questionnaire." Critical Care Medicine, 27, pp.1626-1633.

18. Society of Critical Care Medicine Ethics Committee. "Attitudes of critical care medicine professionals concerning forgoing life-sustaining treatments." Critical Care Medicine. Vol 20, pp.320-326.

19. Fukara, A., Tazawa, H., Nakajima, H., Adachi, M. "Do-not-resuscitate orders at a teaching hospital in Japan." New England Journal of Medicine, Vol 333, pp.805-808.

20. Curtis, J. \& Rubenfeld, G. (2001). Managing Death in the Intensive Care Unit: The Transition from Cure 
to Comfort. New York: Oxford University Press.

21. Youngner, S. (1988). "Who defines futility?" Journal of the American Medical Association, Vol 260, pp.2094-2095.

22. Department of Veterans Affairs National Ethics Committee (1999). Challenges and change.

23. Macmillan,K.D. (2000). Futilitarianism: "Knowing how much is enough in end-of-life health care." Palliative Medicine (July), Vol 14 (4), pp. 313-323.

Notes 